\title{
DADOS INTERFEROMÉTRICOS PARA MODELAGEM TOPOGRÁFICA E CARACTERIZAÇÃO AMBIENTAL DO CAFÉ EM ESCALA MUNICIPAL
}

\author{
Interferometric data for topographic modeling and environmental \\ characterization of coffee crop at municipality scale
}

\begin{abstract}
Marco Aurélio Barros Mestre em Sensoriamento Remoto e Bolsista de Desenvolvimento Tecnológico Industrial do CNPq aurelio@ltid.inpe.br

Maurício Alves Moreira

Pesquisador Instituto Nacional de Pesquisas Espaciais - INPE Mauricio@ltid.inpe br Bernardo Friedrich Theodor Rudorff Pesquisador Instituto Nacional de Pesquisas Espaciais - INPE bernardo@tid.inpe.br
\end{abstract}

Artigo recebido para publicação em 14/03/2007 e aceito para publicação em 08/08/2007

RESUMO: Com a evolução técnica e o acesso gratuito às geotecnologias, constata-se que a utilização dessas ferramentas é imprescindível ao planejamento das atividades agropecuárias com vistas a maximizar o uso dos recursos naturais de forma sustentável. Nesse contexto, as condições fisiográficas de determinada região podem viabilizar ou não a exploração agropecuária trazendo conseqüências diretas na produtividade das culturas e ao meio ambiente. Selecionouse uma área piloto no estado de Minas Gerais compreendendo os municípios de Aguanil, Boa Esperança, Campo Belo e Cristais. Para atingir os objetivos propostos realizou-se um préprocessamento da grade regular SRTM, corrigindo os valores negativos existentes. Em seguida, a grade altimétrica foi associada a um sistema de projeção cartográfica (UTM/SAD69) $e$ organizada em um sistema de informação geográfica de domínio público (SPRING). A partir do pré-processamento e aplicação de métodos derivativos, obteve-se as variáveis declividade e orientação de vertentes espacializadas em formatos numérico (grade regular) e temático. Os resultados permitiram caracterizar as áreas cultivadas com café em relação a estas variáveis.

ABSTRACT: With the recent technical evolution and the free of charge access to several geo technologies, it has been observed that the use of these tools are relevant to the planning of agricultural activities in order to maximize the use of natural resources in a more sustainable manner. In this context, the physiographic conditions of a certain region may or may not allow agricultural exploration bringing direct consequences to crop yield and to the environment. O pilot area was selected in Minas Gerais State comprising the municipalities of Aguanil, Boa Esperança, Campo Belo and Cristais. In order to achieve the proposed objectives a pre-processing with the SRTM regular grid was carried out, to correct for negative values. Following, an altimetry mash was associated to a cartographic projection system (UTM/SAD69) and organized in a geographic information system of public domain (SPRING). From the pre-processing and the 
application of derivative methods, the slope and slope orientation variables were obtained in spatial numerical format (regular mash) and thematic map. The results showed that it was possible to obtaining the coffee crop profile for each municipality with regard to these variables.

Palavras-chave:radar interferométrico SRTM, geotecnologias, modelagem, café; interferometer radar SRTM, geotechnologies, modeling, coffee.

\section{INTRODUÇÃO}

O manejo da cafeicultura consiste num conjunto de operações com o objetivo de propiciar condições favoráveis ao plantio, desenvolvimento e produção de café por tempo indeterminado. Tais operações estão relacionadas diretamente com as condições físicas da área geográfica (solos, declividade, orientação de vertentes), a capacidade de investimento do produtor e adoção de técnicas agronômicas que garantam a manutenção e sanidade de produção. A fisiografia do ambiente é de extrema importância na escolha e no sucesso das atividades agropecuárias, principalmente com vistas ao manejo e mecanização das culturas. Variáveis como solo, relevo e orientação de vertentes podem viabilizar ou não a exploração econômica das culturas agrícolas trazendo conseqüências diretas sobre a produtividade.

Estão indiretamente ligadas à conjuntura econômica, uma vez que o nível tecnológico e a capacidade de investimento na cultura do café são diretamente proporcionais ao retorno do capital por parte do investidor (ABIC, 2005). Dentro desse contexto existem trabalhos que demonstram a importância da utilização de geotecnologias no estudo da aptidão agrícola de terras, manejo de bacias hidrográficas, estudo e modelagem de relevo, análise ambiental de espaços geográficos e zoneamento ecológico econômico. Todos eles enfatizam a importância de imagens orbitais como suporte à extração de dados temáticos (FELGUEIRAS et al., 1988; KURKDJIAN et al., 1992; ZIMBACK, 1997; CREPANI et al., 2001; CREPANI e MEDEIROS, 2004). Porém, os estudos comumente realizados são disponibilizados em pequenas escalas o que não permite um diagnóstico detalhado em escala muni- cipal, gerando prognósticos que não se adequam às condições específicas dos municípios com vistas ao planejamento agrícola local.

Diversos trabalhos que envolveram mapeamentos temáticos e zoneamento ecológico-econômico (CREPANI et al., 2001) utilizaram para a modelagem de terreno cartas topográficas analógicas digitalizadas em sistemas de informação geográfica. Esses dados originalmente analógicos também relatados por VALERIANO et al. (2001), apresentavam alguns inconvenientes como erros sistemáticos inseridos durante a digitalização. Com a disponibilidade dos dados SRTM (Shuttle Radar Topographic Mission) pela NASA (2005) (National Aeronautics and Space Administration), eliminam-se os problemas supracitados, uma vez que as informações da superfície terrestre foram coletadas de forma contínua em formato digital, o que permite diretamente a sua utilização e integração com cenas de sensores multiespectrais como TM-Landsat e CCD-CBERS (VALERIANO, 2004).

O projeto SRTM (Shuttle Radar Topographic Mission) faz parte de um programa científico de longo prazo para estudo da superfície terrestre, oceanos, atmosfera, gelo e vida de uma forma integrada. Os dados SRTM são o resultado de uma missão espacial da NASA, da NIMA (National Imagery and Mapping Agency), da DLR (Agência Espacial Alemã) e da ASI (Agência Espacial Italiana) com o objetivo de gerar um modelo digital de elevação (MDE) da superfície terrestre através de interferometria. Segundo VAN ZYL (2001), os dados SRTM possuem precisão de $16 \mathrm{~m}$ em modo absoluto e $11 \mathrm{~m}$ em modo relativo. Sua missão cobriu toda a superfície terrestre utilizando bandas $\mathrm{C}$ e $\mathrm{X}$, conforme 
EINEDER et al. (2003). Com uma resolução espacial de $90 \mathrm{~m}$, este produto possui maior precisão do que aqueles gerados pelo RADARSAT-1, cuja resolução espacial é de $1000 \mathrm{~m}$ (VALERIANO, 2004).

Para o cálculo das variáveis fisiográficas por meio de ferramentas computacionais e dados coletados por sensores remotos, aplicam-se com freqüência a técnica de representação do terreno denominado modelo numérico de terreno (MNT). Este recurso é definido por uma função matemática que permite a reprodução de uma superfície real a partir de pontos regularmente espaçados. Segundo ASSAD et al. (1998), o modelo está associado à altimetria do terreno, permitindo a representação tridimensional da superfície terrestre.

Com a utilização da grade de altimetria (SRTM) podem-se obter diversas variáveis fisiográficas além da altimetria, como declividade e orientação de vertentes (VALERIANO, 2004). Pensando nesta diversidade de aplicações é que vários autores chamaram a atenção para a necessidade do preparo e processamento dos dados em função dos resultados desejados (LI, 1992; GAO, 1995; ÖZDAMAR et al., 1999; VALERIANO et al., 2001; REISS, 2002). O interesse em trabalhar com os dados SRTM está enfocado na forma de aquisição de dados e sua disponibilização de forma pré-processada e contínua sem falhas para todo o globo terrestre.

Face à lacuna de informações sobre agroecossistemas, desenvolveu-se o presente estudo para suprir a demanda de estudos envolvendo a cafeicultura, atividade econômica de grande importância social e econômica, para permitir o planejamento agrícola local e regional. Parte-se da hipótese de que os dados SRTM podem ser utilizados na modelagem da superfície terrestre como também no cálculo de declividade e orientação de vertentes, e assim, subsidiar estudos em escala municipal.

O objetivo do trabalho é realizar a modelagem topográfica da área de estudo a partir dos dados interferométricos (SRTM) e caracterizar as áreas de cafeicultura, mapeadas em escala municipal, em relação às variáveis altimetria, declividade e orientação de vertentes.

\subsection{Relevo e Cafeicultura}

O relevo, no contexto de implantação e condução da cafeicultura é de grande importância principalmente com vistas à mecanização e à conservação do solo.

AMARAL et al. (1999) e SEDIYAMA et al. (2001) relataram em seus trabalhos que os solos adequados ao cultivo do cafeeiro são os profundos, porosos e bem drenados, com uma estrutura granular de tamanho médio, moderadamente desenvolvido com textura média, não sendo recomendados solos com teor de argila menor que $20 \%$ e, quando muito argilosa, devem apresentar estrutura e porosidade favorável à boa infiltração de água. Nesse sentido, MATIELLO (1991) comentou que as áreas com declividade até $20 \%$ podem ser mecanizadas sem restrições, o que enquadra os Argissolos e Latossolos como as terras em que a cafeicultura dispõe de melhores condições de cultivo, com exceção de áreas com a ocorrência de Argissolos variação rasa cascalhenta, presente em algumas áreas, por exemplo, nos municípios de Aguanil e Campo Belo. Ambos (Argissolos e Latossolos) são caracterizados pela boa profundidade efetiva, com drenagem eficiente e facilmente mecanizáveis, mas nessa região possuem baixa fertilidade natural devido ao caráter distrófico.

ALZUGARAY e ALZUGARAY (1984) recomendam para o plantio de café áreas com vertentes orientadas ao norte, uma vez que o planeta Terra descreve, observando-se o hemisfério sul, uma ligeira curva em direção ao norte, mais acentuada no período de inverno. Portanto as terras com face norte recebem maior irradiância solar do que em terrenos de face sul. Recomenda-se então plantar café em áreas com face voltada para o norte ou noroeste/ nordeste. Caso o plantio ocorra em áreas com face nordeste, o terreno receberá maior irradiância solar no período da manhã e em áreas com face noroeste, maior irradiância solar no período da tarde. A face sul é desaconselhada ao plantio de café, devido à 
maior umidade e maior incidência de ventos frios na época de inverno. Não são recomendados plantios de cafeeiros em altitude inferior a $500 \mathrm{~m}$ e superior a 1200 m conforme SEDIYAMA et al. (2001).

\section{MATERIAL E MÉTODOS}

A área de estudo compreende quatro municípios de Minas Gerais: Aguanil, Boa Esperança,
Campo Belo e Cristais, localizados no sudoeste do Estado ocupando uma área total de $2.253 \mathrm{~km} 2$, conforme a Figura 1. Os municípios foram selecionados devido à heterogeneidade da cultura do café perante às características fisiográficas e nível tecnológico de instalação das lavouras. A Tabela 1 apresenta a área de café cultivada em cada um dos municípios estudados.

Tabela 1. Área de café cultivada nos municípios em estudo.

\begin{tabular}{c|c}
\hline Municípios & Área de Café (ha) \\
\hline Aguanil & 1.099 \\
Boa Esperança & 13.990 \\
Campo Belo & 4.006 \\
Cristais & 5.806 \\
Total & 24.901 \\
\hline
\end{tabular}

Fonte: BARROS (2006)

Figura 1. A (Cristais), B (Campo Belo), C (Aguanil), D (Boa Esperança), - TM/Landsat TM7(R) TM4(G) TM3(B).

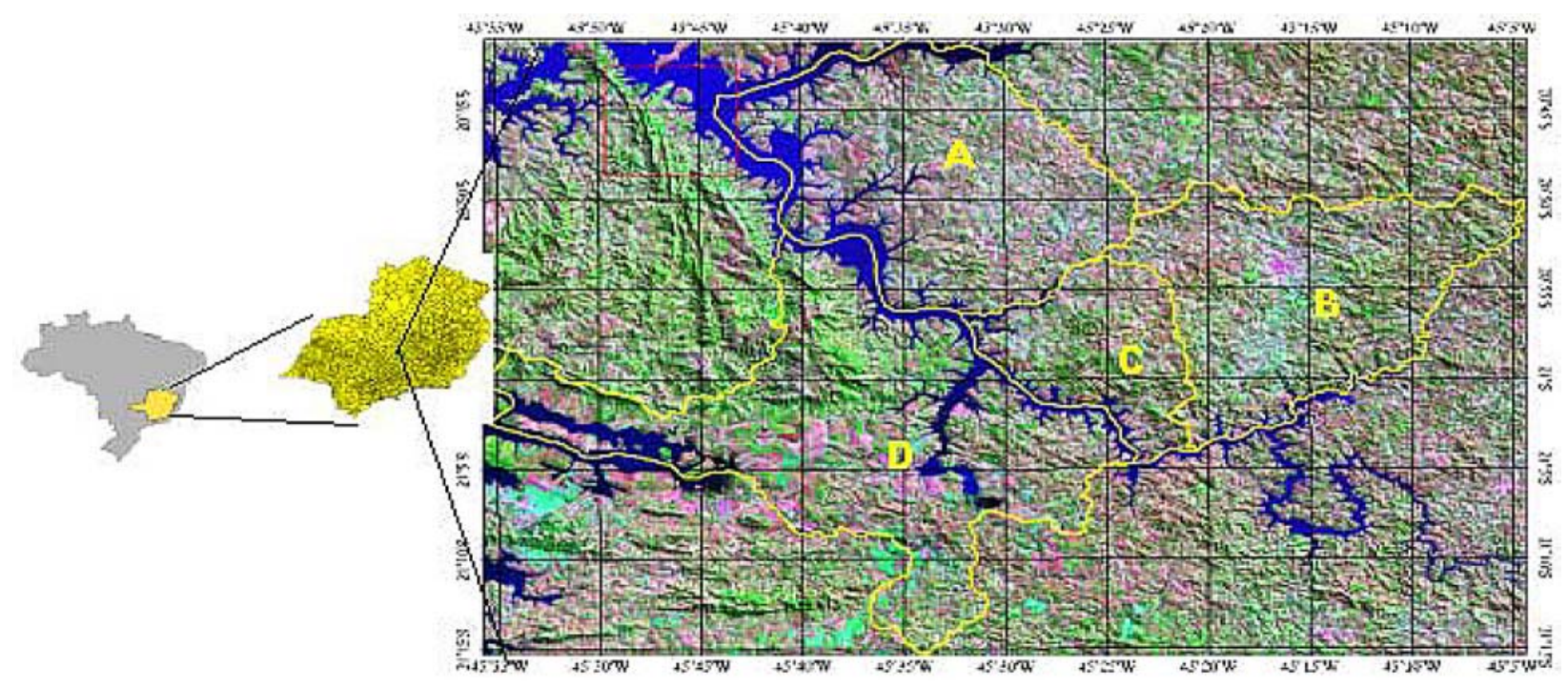

Sociedade \& Natureza, Uberlândia, 19 (2): 33-50, dez. 2007 
Os materiais utilizados estão apresentados

na Tabela 2.

Tabela 2. Materiais utilizados no estudo.

\begin{tabular}{|c|c|c|c|}
\hline ITEM & DESCRIÇÃO & QUANTIDADE & ESPECIFICAÇÕES (Fonte) \\
\hline 1.0 & Cartografia & & \\
\hline 1.1 & Limite Municipal & 3 & 1:100.000 (PRODEMGE, 1998) \\
\hline 1.2 & Carta Topográfica & 3 & 1:50.000 (IBGE, 2005) \\
\hline 1.3 & Mapa de Solos & 1 & 1: 250.000 (BARROS, 2006) \\
\hline 1.4 & Mapa de Cafeicultura & 1 & 1:100.000 (BARROS, 2006) \\
\hline 2.0 & Modelagem de Terreno & & \\
\hline 2.1 & Grade SRTM & 2 & S21W046 e S22W046 (NASA, 2005) \\
\hline 3.0 & Aplicativos & & \\
\hline 3.1 & Spring & 1 & SIG (CÂMARA et al.,1996) \\
\hline 3.2 & Envi & 1 & SIG (ENVI, 2004) \\
\hline 3.3 & Minitab & 1 & Estatística (MINITAB, 2000) \\
\hline
\end{tabular}

Vários métodos foram desenvolvidos neste trabalho e podem ser resumidos em duas etapas: a) Processamento dos dados SRTM; b) Geoprocessamento entre as áreas de café mapeadas e as variáveis fisiográficas.

\subsection{Modelagem Digital do Terreno - Processamento dos dados SRTM}

A Figura 2 ilustra todas as etapas desenvolvidas na modelagem de terreno, detalhadamente explicadas a seguir.

Figura 2. Fluxograma das etapas de processamento dos dados SRTM.

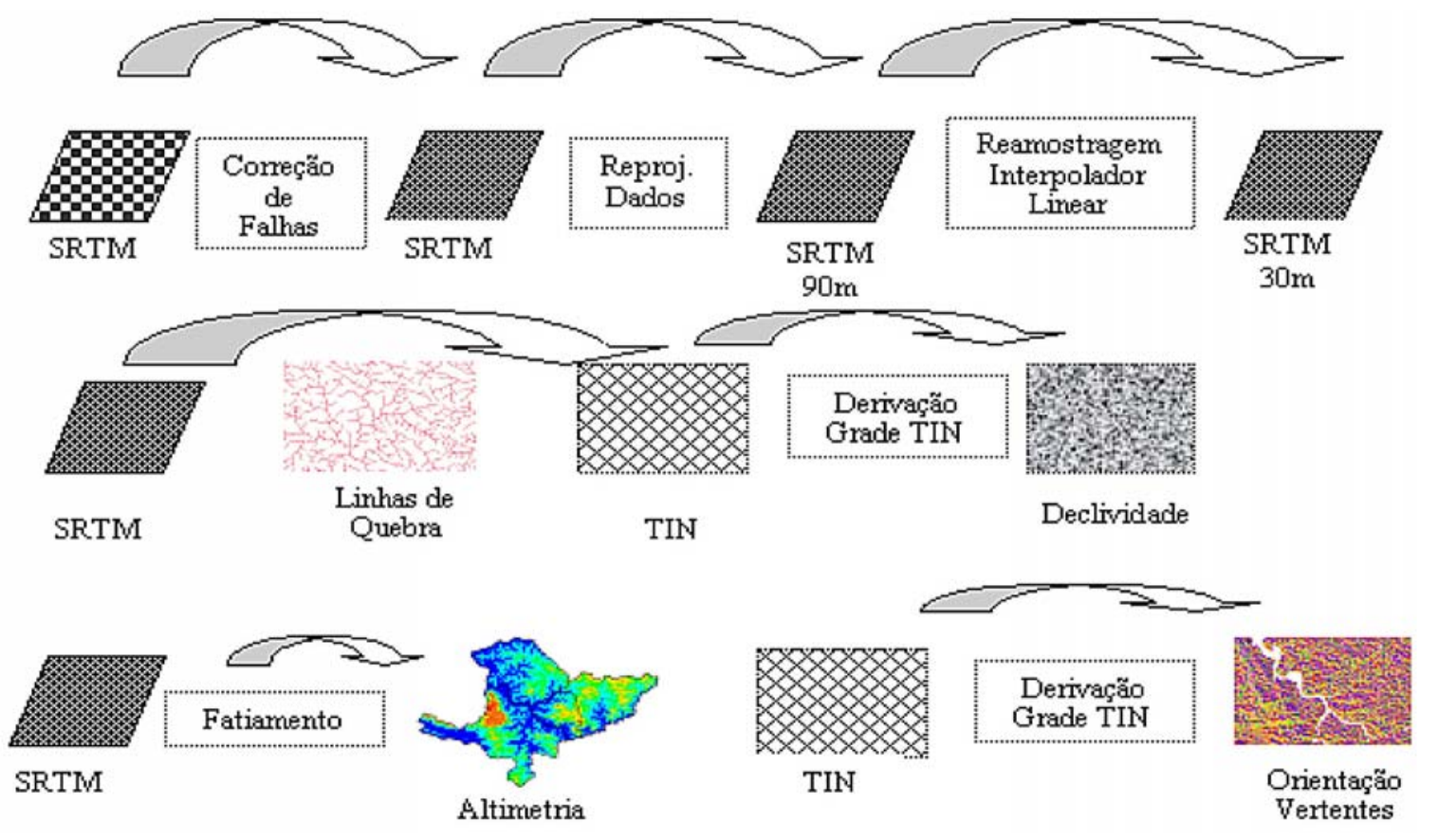

Sociedade \& Natureza, Uberlândia, 19 (2): 33-50, dez. 2007 
A primeira etapa necessária à utilização da grade regular com valores de altimetria (SRTM) correspondeu à correção de valores incorretos representados na grade numérica como valores negativos, preteritamente relatados por VALERIANO (2004). Os valores negativos foram provocados pela reflexão especular da energia eletromagnética emitida pelo sensor ativo principalmente em áreas de corpos d’água, como o lago de Furnas. Para eliminar o problema, realizou-se a substituição dos valores negativos da grade regular por meio de um interpolador do tipo Delaunay, que calcula o novo valor da cota altimétrica do pixel através do processo de triangulação com os pixels vizinhos.

Eliminados os valores negativos supracitados, alterou-se a projeção e datum original da grade regular SRTM de Lat-Long/WGS84 para UTM/ SAD69 para adequar-se ao banco de dados geográ- ficos. Com os dados na projeção e datum desejados, gerou-se isolinhas com eqüidistância de $45 \mathrm{~m}$, obtendo-se na seqüência uma grade triangular com resolução espacial de $90 \mathrm{~m}$, considerando a drenagem nesta operação como linha de quebra. Utilizou-se o método de triangulação por Delaunay com modificação por menor ângulo entre as normais conforme CREPANI et al. (2004). A partir da grade triangular, gerou-se uma grade retangular com resolução espacial de 30 $\mathrm{m}$, utilizando-se um interpolador bilinear indicado por CREPANI et al. (2004) e calculou-se a declividade. O cálculo da declividade é realizado por filtragem através de máscaras móveis, explorando-se a função de derivação na vizinhança de cada célula da grade altimétrica. Utilizou-se uma máscara padrão de 3 x 3 pixels que percorre a grade regular calculando novos valores para cada pixel. Os valores originais de altimetria são substituídos por valores de declividade. Matematicamente o cálculo está ilustrado na Figura 3.
A

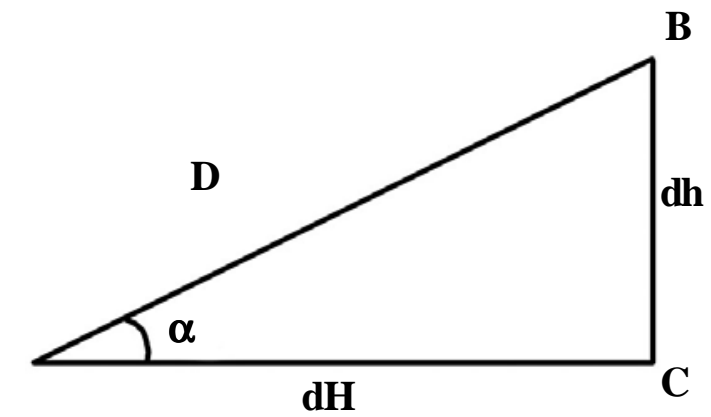

$\mathrm{dh}=$ diferença da altura BC

$\mathrm{dH}=$ distância horiz. AC

$D=d h / d H$

Figura 3. Representação matemática do cálculo da declividade a partir dos dados SRTM.

Para o cálculo da orientação de vertentes, a parametrização da superfície terrestre foi realizada em uma grade numérica, dividida em quatro quadrantes no sentido azimutal, no qual 0 o corresponde no contexto à direção norte, com os valores aumentando no sentido horário, fechando o quadrante em 360o (WOOD, 1996). Neste processo, são obtidas duas variáveis resultantes de cálculos derivativos sobre a grade triangular com 30 m de resolução espacial: a primeira variável corresponde ao gradiente e a segunda denomina-se exposição. Segundo o mesmo autor, o gradiente corresponde ao cálculo da declividade (Figura 4), enquanto a exposição (Equação 1) representa a direção da variação da declividade em cada quadrante, calculada pela derivada de segunda ordem, em que A (exposição); x e y (coordenadas axiais); z (altimetria); $\mathrm{p}$ (180 graus).

$$
\tan A=\left(\frac{-\partial z}{\partial x} / \frac{\partial z}{\partial y}\right),(-\pi<A<\pi)
$$

Para cada ponto da grade altimétrica com resolução espacial de $30 \mathrm{~m}$ foram calculadas as derivadas parciais, computando-se os valores de altitude em uma janela de $3 \times 3$ pixels que se desloca sucessivamente sobre a grade altimétrica. $\mathrm{O}$ resultado foi representado em um plano de informação numérico com valores compreendidos entre $0^{\circ}$ e $360^{\circ}$ na direção azimutal, representando tridimensionalmente a superfície do terreno. 
Obtidas as variáveis supracitadas, procedeuse uma operação de fatiamento, com a definição dos intervalos de classes temáticas para as variáveis declividade, orientação de vertentes e altimetria, representados em mapas temáticos conforme a Tabela
3. As faixas de declividade, orientação de vertentes e altimetria foram selecionadas a partir da situação dos municípios em estudo, o que permite a realização de estudos comparativos.

Tabela 3. Variáveis mapeadas e respectivas classes temáticas de representação.

\begin{tabular}{l|c|c}
\hline DECLIVIDADE(\%) & ORIENTAÇÃO DE VERTENTES(graus) & ALTIMETRIA(m) \\
\hline 0 a 10,9 & 0 a $45(\mathrm{~N}-\mathrm{NE})$ & 743 a 800,9 \\
11 a 15,9 & 45,1 a 90 (NE-E) & 801 a 850,9 \\
16 a 20,9 & 90,1 a $135(\mathrm{E}-\mathrm{SE})$ & 851 a 900,9 \\
21 a 25,9 & 135,1 a $180(\mathrm{SE}-\mathrm{S})$ & 901 a 950,9 \\
26 a 50,9 & 180,1 a $225(\mathrm{~S}-\mathrm{SW})$ & 951 a 1000,9 \\
51 a 75,9 & 225,1 a $270(\mathrm{SW}-\mathrm{W})$ & 1100 a 1200,9 \\
76 a 100 & 270,1 a $315(\mathrm{~W}-\mathrm{NW})$ & 1201 a 1300,9 \\
$>100$ & 315,1 a $360(\mathrm{NW}-\mathrm{N})$ & 1301 a 1410,9 \\
\hline
\end{tabular}

\subsection{Geoprocessamento entre as variáveis temáticas}

A Figura 4 ilustra as principais operações e procedimentos na obtenção dos mapas envolvendo cafeicultura e as variáveis fisiográficas, utilizando operações booleanas, conforme descrito por BURROUGH e MCDONNELL (1998). Nesta operação, caracterizada como binária, o resultado é representado pelo conjunto de informações contidos nas áreas de café, neste caso as variáveis solo, altimetria, declividade e orientação de vertentes. Com essa operação, foi possível estabelecer as faixas de declividade, altimetria, solos e orientação de vertente onde o café é cultivado.

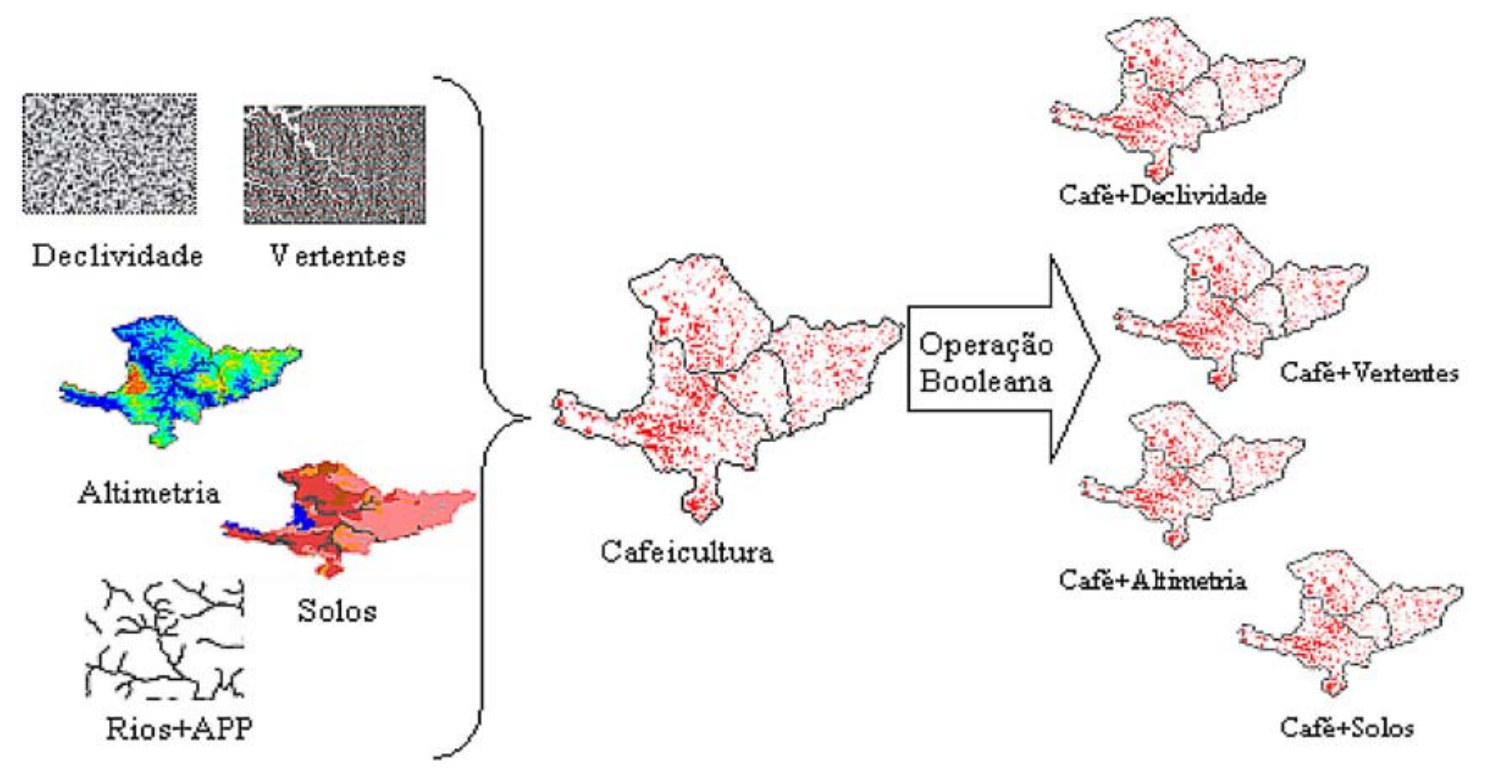

Figura 4. Fluxograma para a obtenção dos mapas de sobreposição entre variáveis fisiográficas e cafeicultura. 


\section{RESULTADOS}

\subsection{Modelagem do Terreno: Altimetria, Declividade e Orientação de Vertentes}

Campo Belo é o município com maior média de altimetria. O município com maior variabilidade no relevo é Boa Esperança, devido à presença da Serra de Boa Esperança confirmada estatisticamente pelo coefi- ciente de variação e amplitude altimétrica. Os valores de média, desvio padrão, coeficiente de variação, valores máximo e mínimo estão disponíveis na Tabela 4.

O município com a menor média de altimetria é Cristais, seguido por Aguanil e Boa Esperança. A maior variabilidade do relevo foi observada em Boa Esperança representada pelo maior coeficiente de variação.

Tabela 4. Estatísticas descritivas para a variável altimetria.

\begin{tabular}{l|c|c|c|c}
\hline \multirow{2}{*}{} & \multicolumn{4}{|c}{ Altimetria (metros) } \\
\cline { 2 - 5 } & Aguanil & Boa Esperança & Campo Belo & Cristais \\
\hline Média & 843,8 & 847,5 & 862,4 & 814,4 \\
Desvio Padrão & 63,5 & 101,4 & 53,0 & 36,9 \\
Coeficiente de Variação & 7,5 & 11,9 & 6,15 & 4,5 \\
Valor Máximo & 1090,3 & 1399,2 & 1074,2 & 1023,9 \\
Valor Mínimo & 755,4 & 755,8 & 754,8 & 751,1 \\
\hline
\end{tabular}

A Figura 5 ilustra a representação em nível de cinza da variável altimetria com a represen- tação temática segundo classes apresentadas na Tabela 3.

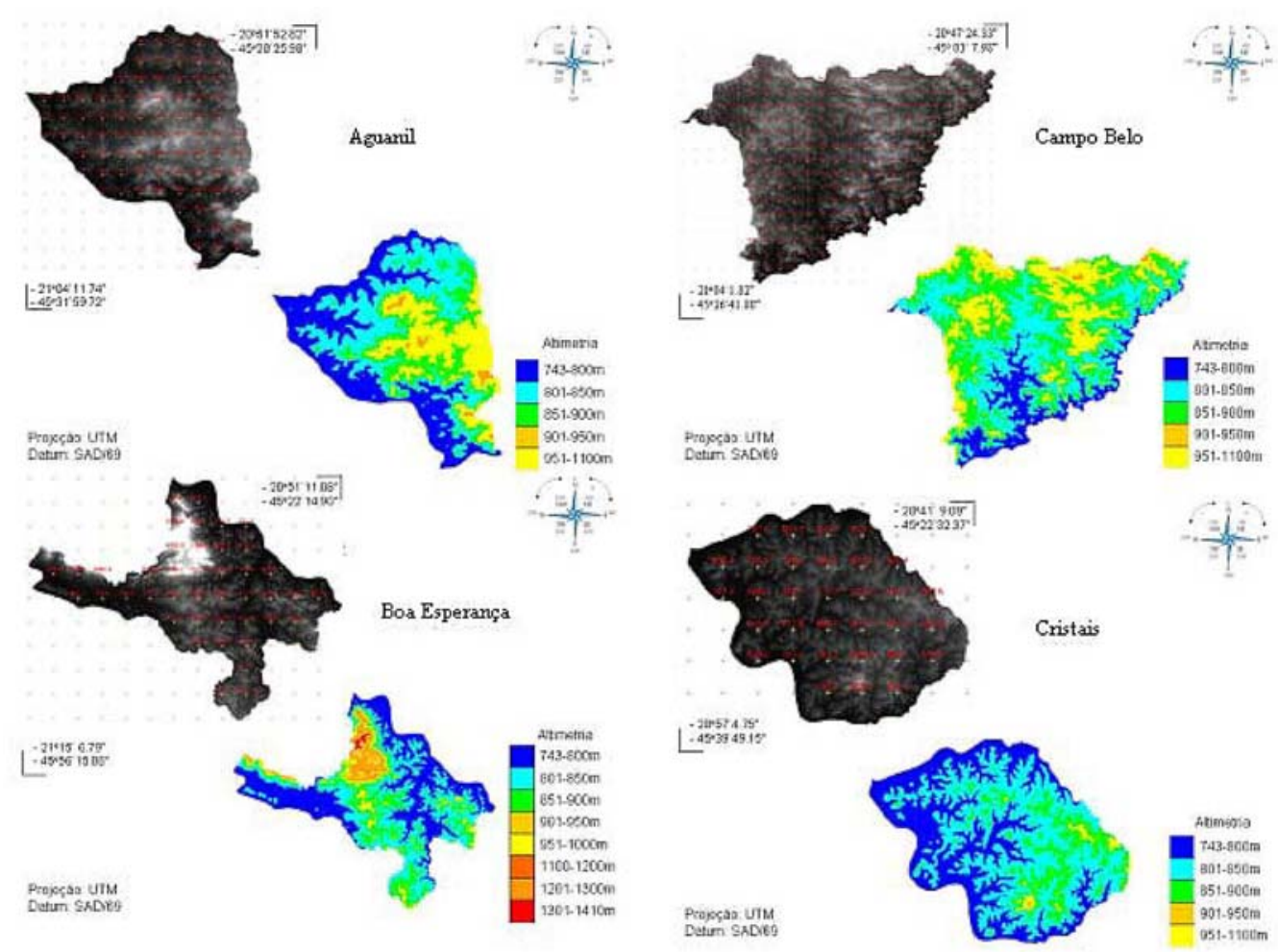

Figura 5. Representações em nível de cinza dos valores de altimetria na área de estudo.

Sociedade \& Natureza, Uberlândia, 19 (2): 33-50, dez. 2007 


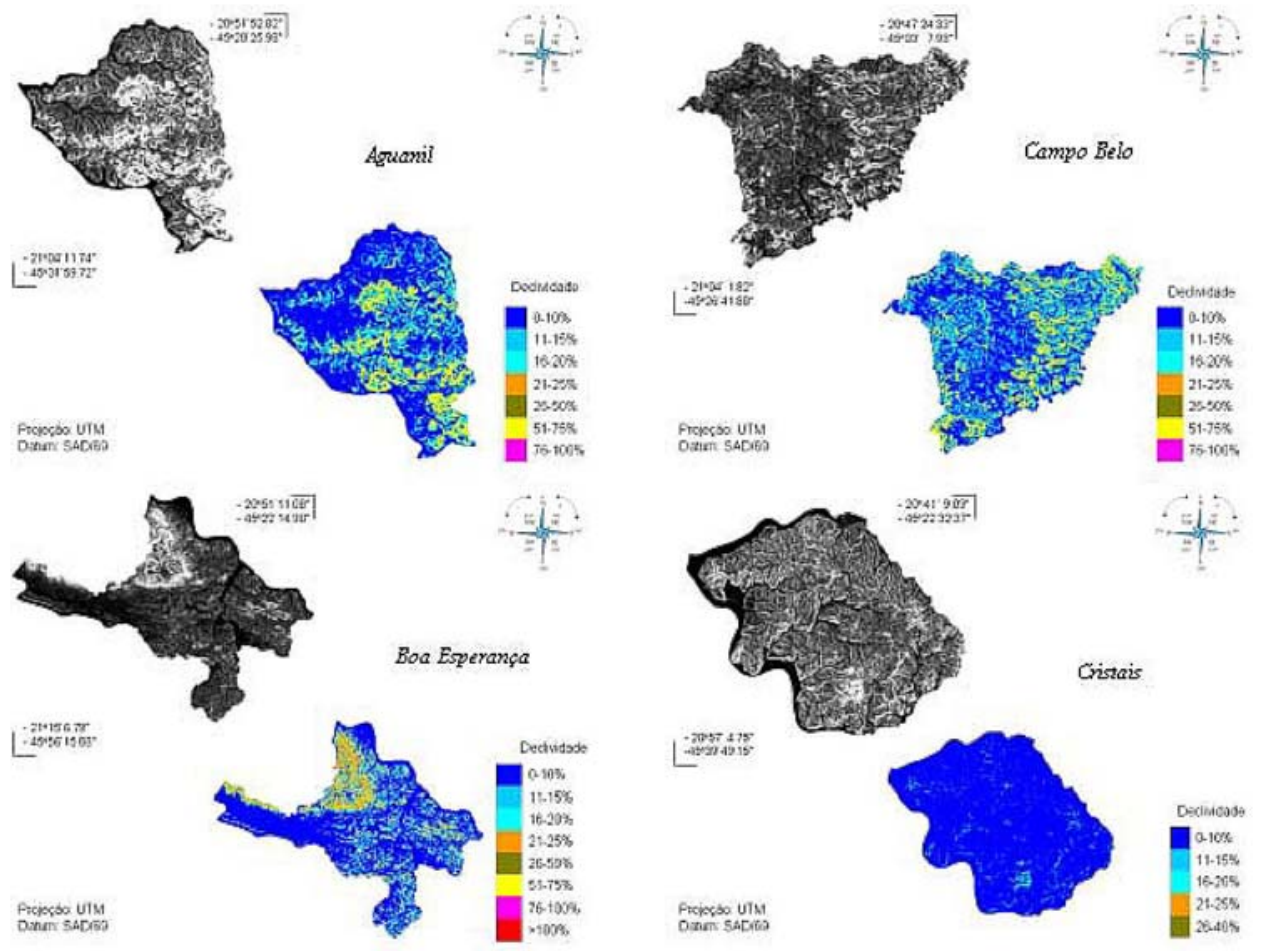

Figura 6. Mapas de declividade ilustrando os municípios em estudo.

Na seqüência, são apresentados os mapas de declividade estratificados por município (Figura 6) e as estatísticas descritivas para a mesma variável. Em relação à variável declividade, o município com a maior amplitude e variabilidade é Boa Esperança, devido à presença da Serra da Boa Esperança, que pode ser visualizada na Figura 5 como a área mais clara na representação em nível de cinza no município. Os valores mais claros representam as altas freqüências, ou seja, áreas com declividade mais acentuada e as áreas mais escuras aquelas com menor declividade.
Pode-se verificar na Figura 6 que todos os municípios possuem relevo com alta amplitude de declividade. Nota-se visualmente que Cristais éo município de menor variabilidade no relevo, confirmado pelas estatísticas descritivas disponíveis na Tabela 4.

Observa-se na Tabela 5 que o município com a maior média de declividade é Campo Belo. Porém, o município com a maior amplitude de declividade é Boa Esperança devido à presença da Serra de Boa Esperança, cuja representação em nível de cinza ressalta as altas freqüências do relevo.

Tabela 5. Estatísticas descritivas para a variável declividade.

\begin{tabular}{l|c|c|c|c}
\hline \multirow{2}{*}{} & \multicolumn{4}{|c}{ Declividade (\%) } \\
\cline { 2 - 5 } & Aguanil & Boa Esperança & Campo Belo & Cristais \\
\hline Média & 12 & 11 & 13,6 & 5,1 \\
Desvio Padrão & 9 & 10 & 9 & 3 \\
Coeficiente de Variação & 76 & 94 & 65 & 66 \\
Valor Máximo & 100 & 188 & 101 & 32 \\
Valor Mínimo & 0 & 0 & 0 & 0 \\
\hline
\end{tabular}


Para o cálculo da variável orientação de vertentes, considerou-se em sua representação que $o$ valor 0 o corresponde à orientação norte; $45^{\circ}$ orientação à nordeste; $90^{\circ}$ orientação à leste; $135^{\circ}$ orientação à sudeste; $180^{\circ}$ orientação ao sul; $225^{\circ}$ orientação à sudoeste; $270^{\circ}$ orientação de vertentes a oeste; $315^{\circ}$ orientação de vertentes a noroeste e novamente retornando a posição inicial em 360o (norte). Os valores intermediários aos intervalos supramencionados, serão agrupados ao intervalo do quadrante correspondente conforme Figura 7.

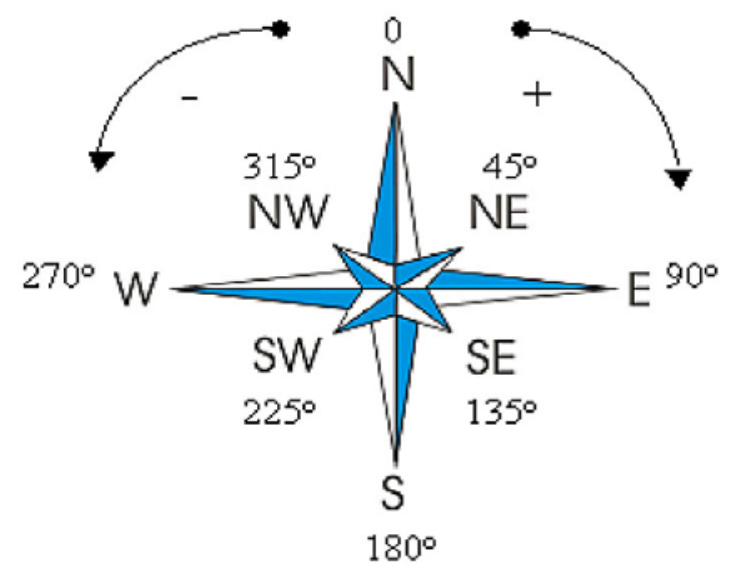

Figura 7. Representação dos valores calculados da variável orientação de vertentes.

Na Figura 8 são apresentados os resultados do cálculo da variável orientação de vertentes, com a representação em nível de cinza e temáticos em classes agrupadas segundo os intervalos apresentados na Tabela 2. Pode-se inferir que os municípios
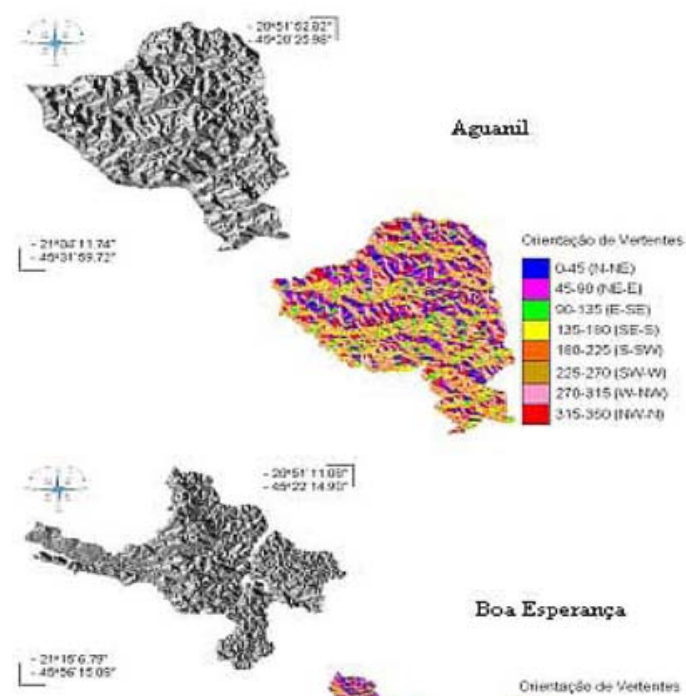

Boa Esperança

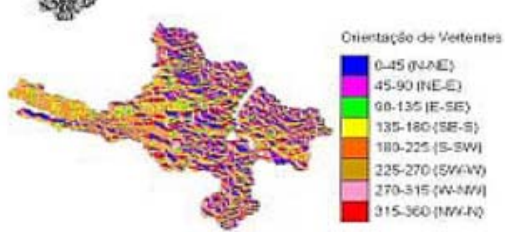

possuem topografia bem acidentada, com as áreas mais planas localizadas em Boa Esperança e Cristais. A visão sinóptica do terreno através do cálculo dessa variável permite observar com detalhes a sua aparência ondulada.
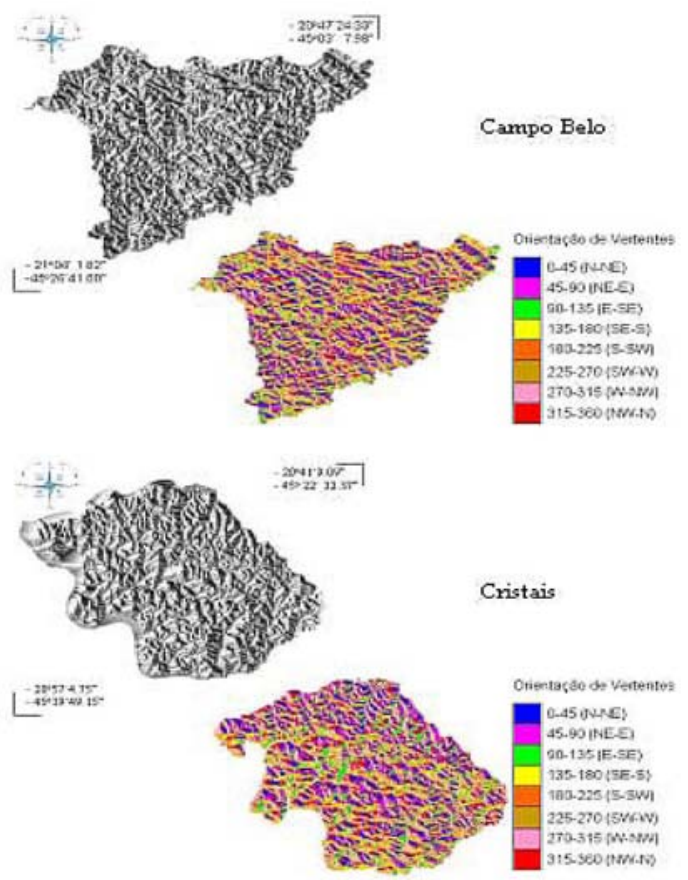

Figura 8. Mapas numéricos e temáticos ilustrando a variável orientação de vertentes.

Sociedade \& Natureza, Uberlândia, 19 (2): 33-50, dez. 2007 
O município de Aguanil possui relevo com orientação de vertentes bem diversificadas. A maior parte do município possui orientação de vertentes à noroeste e as áreas com menor freqüência estão orientadas a sudeste conforme histograma na Figura
9, letra C e B respectivamente. Infere-se que grande parte do município pode ser considerada adequada ao plantio de cafezais, observando somente a variável supramencionada.

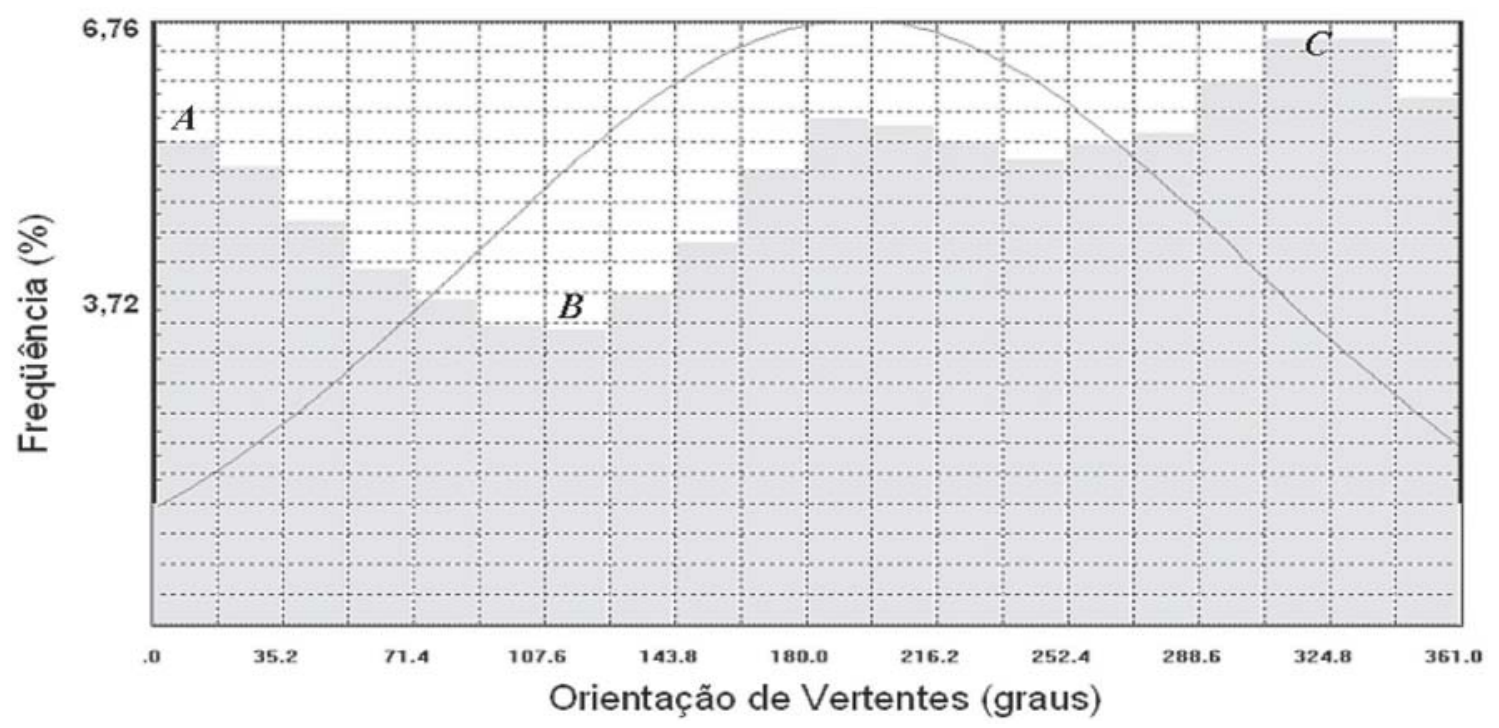

Figura 9. Histograma com a freqüência de ocorrência da orientação de vertentes em Aguanil.

O município de Boa Esperança possui relevo com orientação de vertentes diversificada conforme atesta o histograma na Figura 11. A orientação de vertentes ao sul é a predominante no município, confor- me Figura 10, letra C. Na seqüência, destacam-se as áreas com orientação de vertentes a nordeste e noroeste (A e D, respectivamente), com as menores freqüências de valores em relação à vertente sudoeste (B).

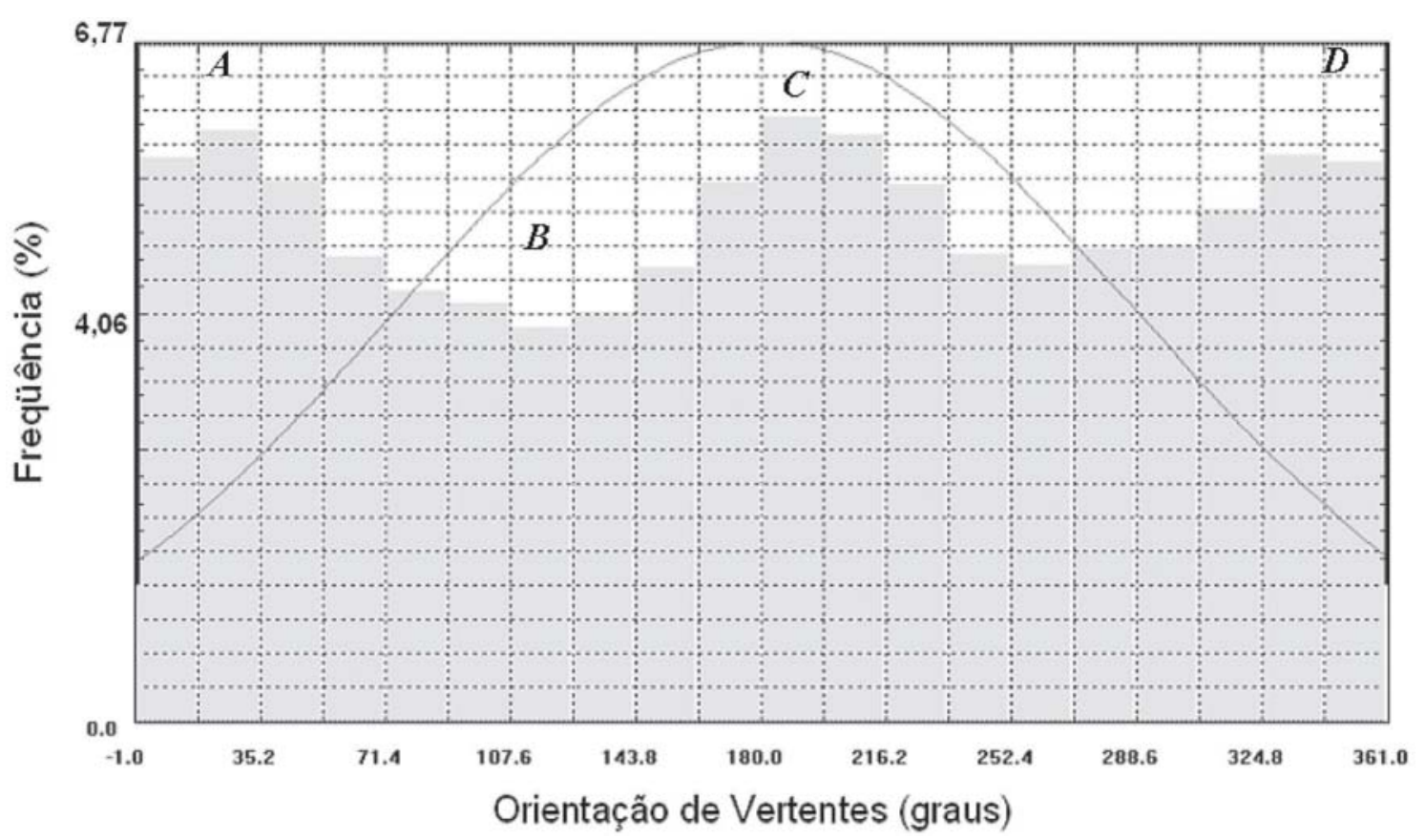

Figura 10. Histograma com a freqüência de ocorrência da orientação de vertentes em Boa Esperança. 
No município de Campo Belo, a vertente de maior freqüência está na direção sudeste (B), e áreas com menor freqüência à noroeste (C), representados na Figura 11.

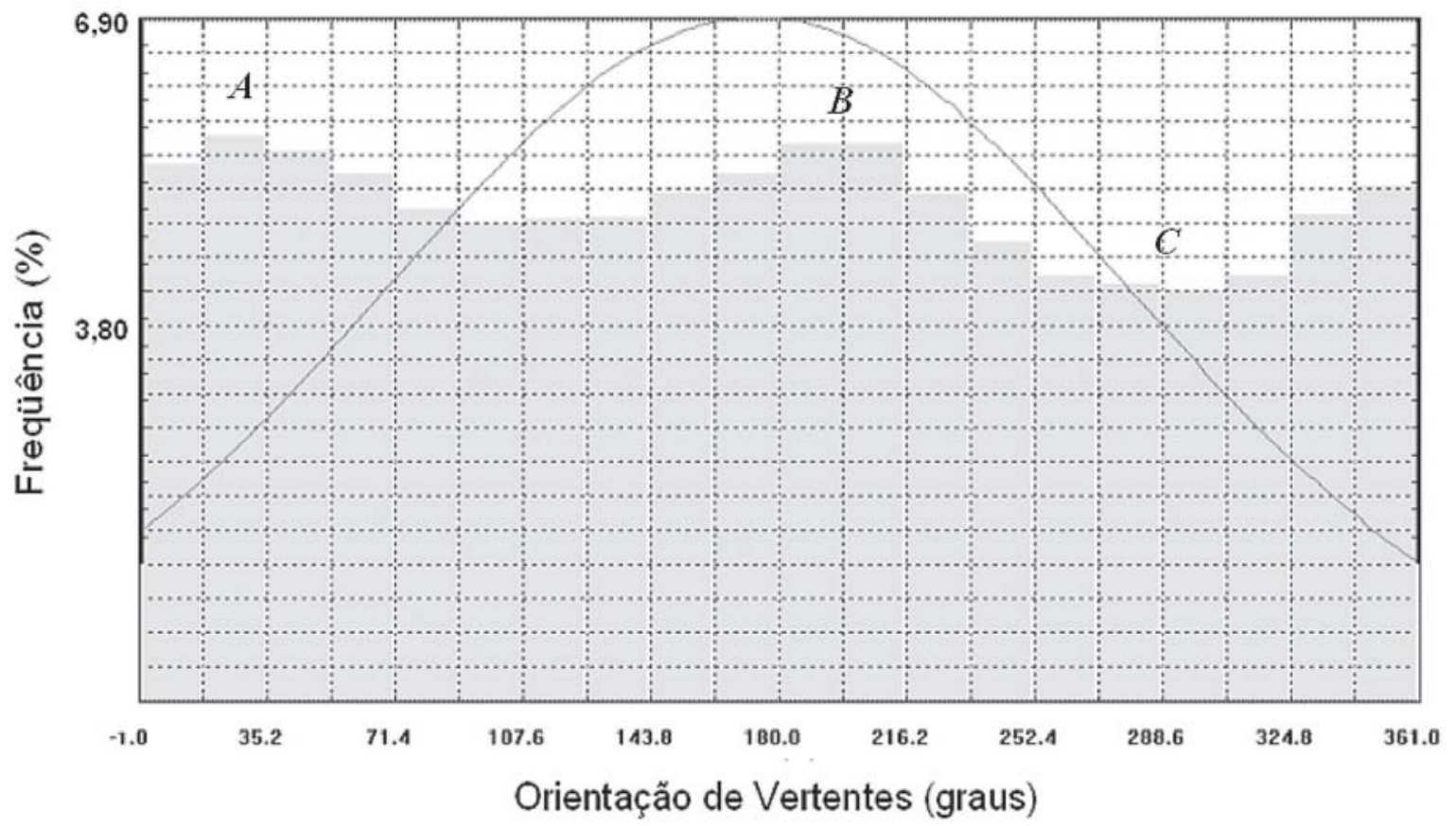

Figura 11. Histograma com a freqüência de ocorrência da orientação de vertentes em Campo Belo.

Em relação ao município de Cristais há maior freqüência de áreas com orientação de vertentes na direção noroeste conforme histograma na Figura 12, (A). As áreas com menor freqüência estão orientadas à sudeste (B). Esse perfil indica que o município apresenta condições propícias à cafeicultura, considerando somente a variável supracitada.

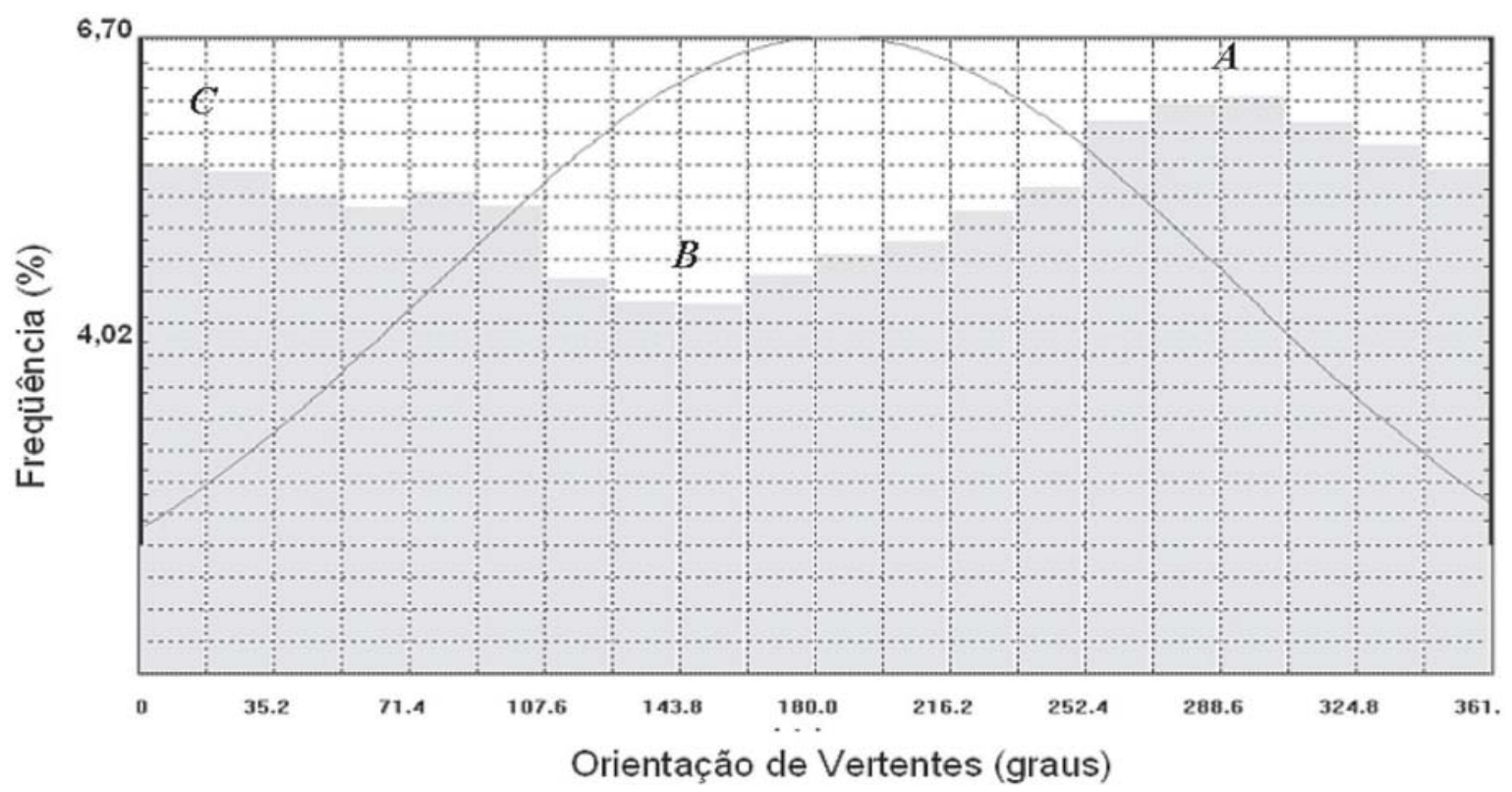

Figura 12. Histograma com a freqüência de ocorrência da orientação de vertentes em Cristais. 
Os municípios de Aguanil e Cristais possuem as maiores freqüências de áreas orientadas a nordeste e noroeste enquanto Boa Esperança e Campo Belo predominam vertentes orientadas ao sul e sudoeste, respectivamente. Se considerarmos a variável orientação de vertentes e sua importância para a cafeicultura, conclui-se que se deve plantar café preferencialmente em áreas com orientação de vertentes ao norte, nordeste e noroeste. São áreas menos suscetíveis a eventos climáticos adversos e com maior irradiância solar, e conseqüentemente maior atividade fotossin- tética fornecendo condições propícias à cultura.

\section{CARACTERIZAÇÃO AMBIENTAL DA CAFEICULTURA}

\subsection{Solos e Cafeicultura}

A Figura 13 ilustra a distribuição espacial dos solos na região de estudo e, a Figura 14 ilustra a distribuição relativa dos solos em nível municipal.

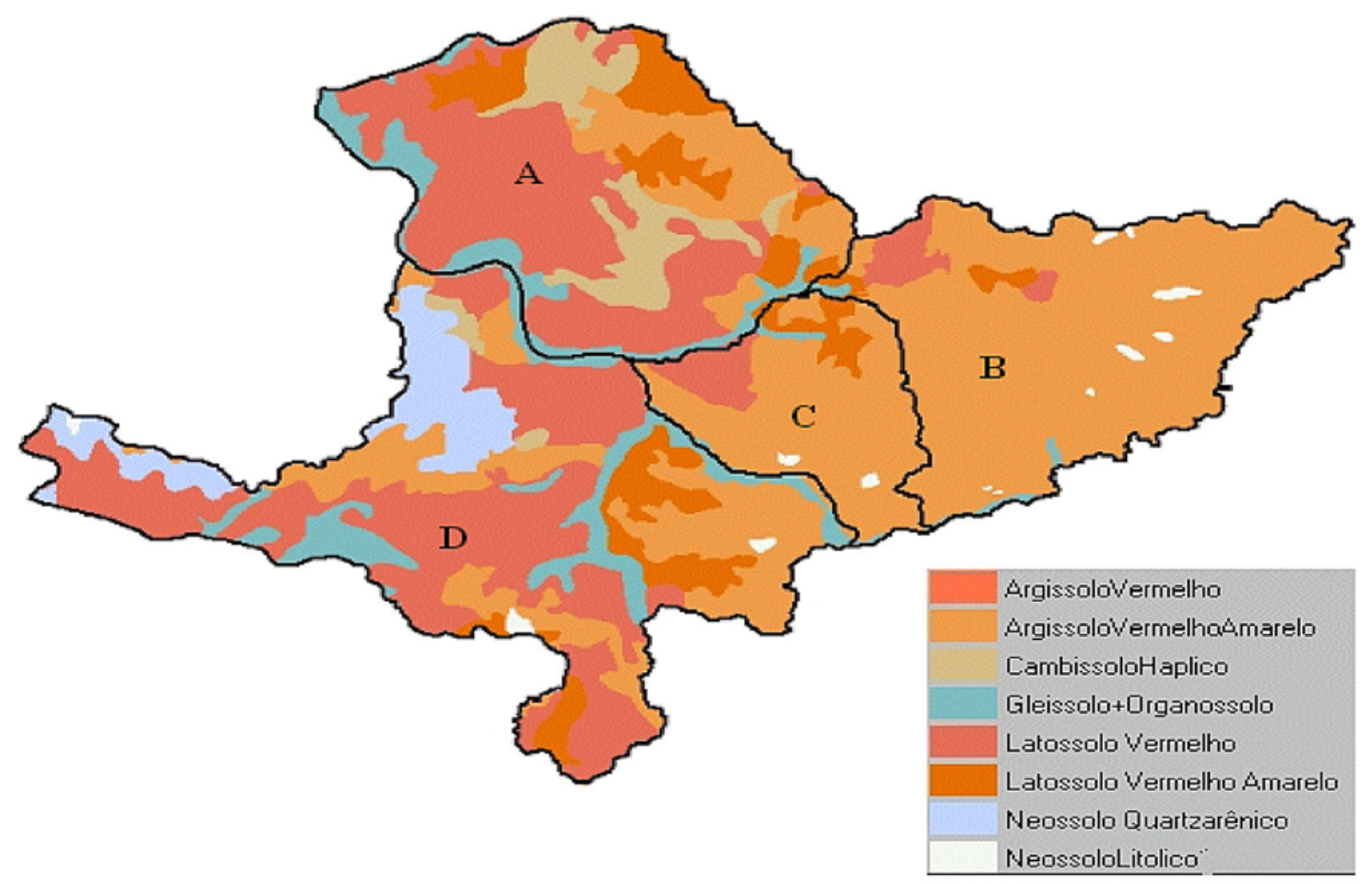

Figura 13. Mapa de solos nos municípios de A (Cristais), B (Campo belo), C (Aguanil) e D (Boa Esperança) conforme Barros (2006).

Observa-se na Figura 14, que Argissolo Vermelho Amarelo é o solo com a maior área de cafeicultura nos municípios de Aguanil e Campo Belo, com 70,9\% e 90,6\% respectivamente. Já em relação aos municípios de Boa Esperança e Cristais, o solo mais cultivado com café é o Latossolo Vermelho, com $56 \%$ e $62,2 \%$ respectivamente. Ambos (Argissolos e Latossolos) são de baixa a média fertilidade, aptos à exploração com cafeicultura e facilmente mecanizáveis, com restrições de conservação e manejo principalmente em relação ao Argissolo Verme- lho Amarelo, de textura mista e relevo mais movimentado do que as áreas de Latossolo Vermelho. $\mathrm{O}$ solo com menor porcentagem de cafeicultura é o Gleissolo+Organossolo, que apresenta restrições à mecanização e exploração agrícola.

Ressalta-se ainda que ficou evidente na Figura 14, que os municípios formam dois agroecossistemas cafeeiros semelhantes: o primeiro engloba os municípios de Aguanil e Campo Belo e o segundo, engloba Boa Esperança e Cristais. 
Dados interferométricos para modelagem topográfica e caracterização ambiental do café em escala municipal Marco Aurélio Barros, Maurício Alves Moreira, Bernardo Friedrich Theodor Rudorff

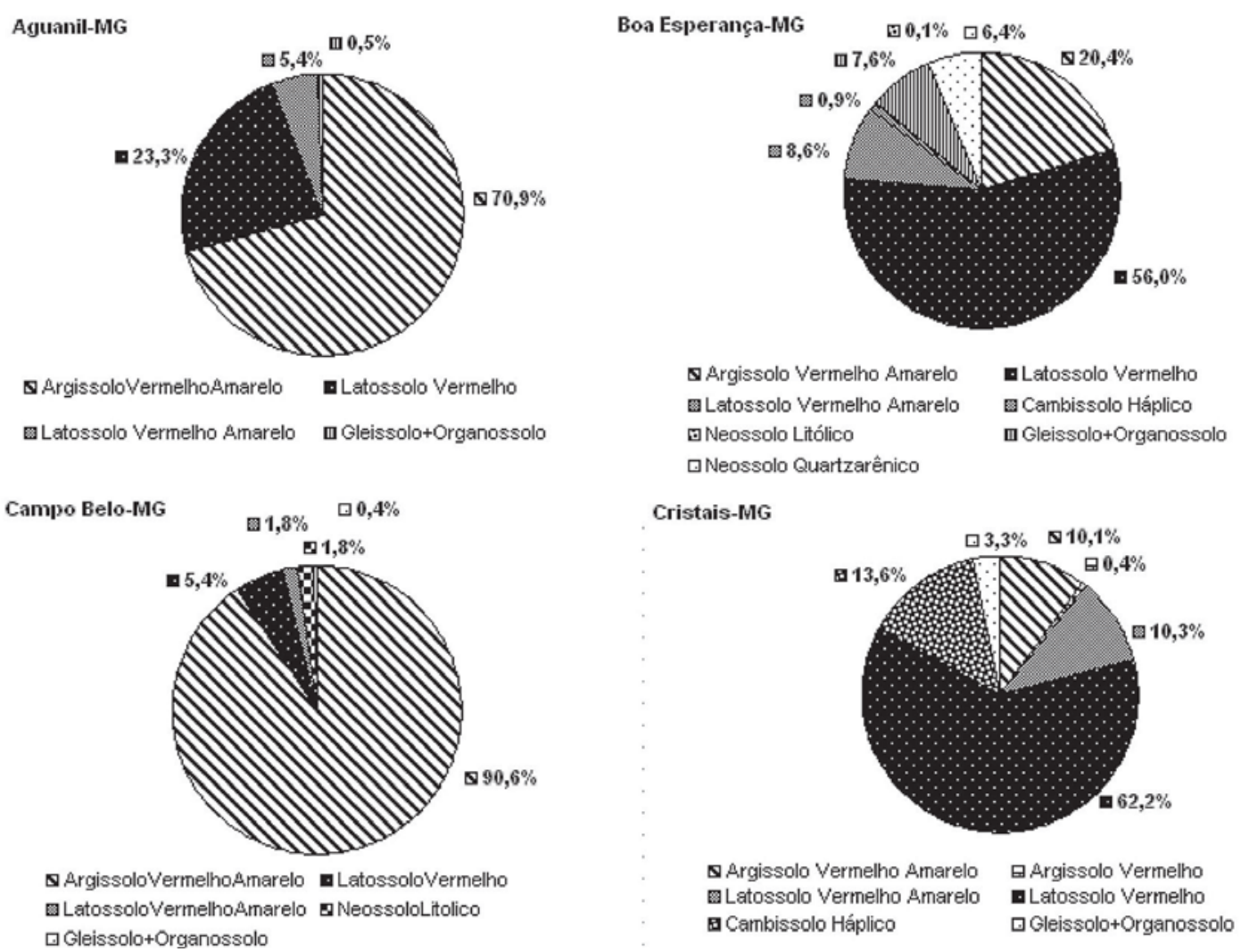

Figura 14. Distribuição quantitativa dos solos cultivados com café em escala municipal.
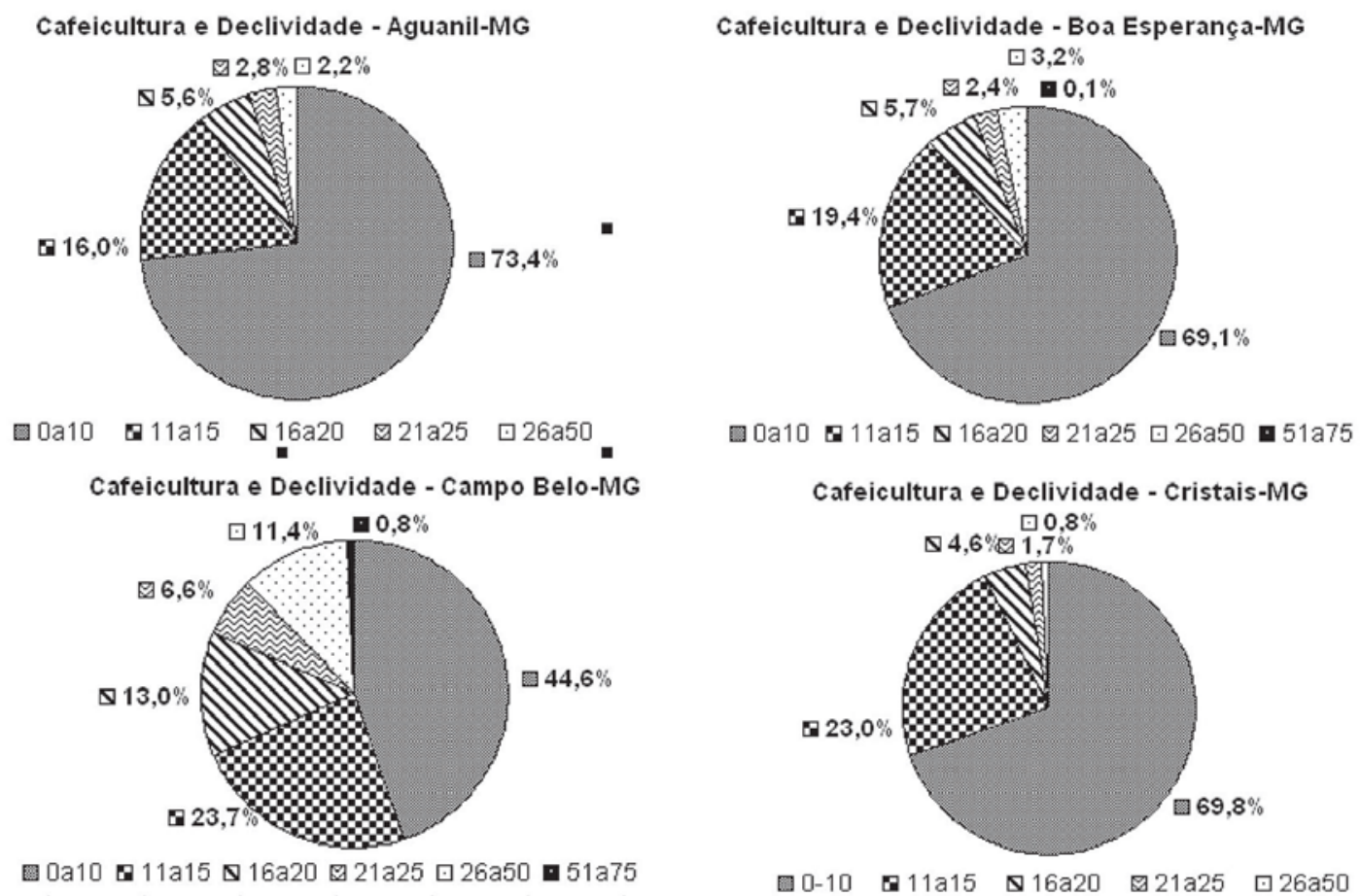

Figura 15. Caracterização da cafeicultura nos municípios em estudo em relação à declividade.

Sociedade \& Natureza, Uberlândia, 19 (2): 33-50, dez. 2007 


\subsection{Declividade e Cafeicultura}

Conforme os gráficos na Figura 15, notouse um padrão na instalação das áreas cafeeiras em relevo com até $10 \%$ de declividade, indicados para a mecanização da cultura e normalmente localizados em solos mais permeáveis com ausência de limitações físicas na região em estudo. Em Aguanil, 73\% das áreas de café estão instaladas em declividade entre 0 a 10\%. Em Boa Esperança, 69\% das áreas estão instaladas em áreas entre 0 e $10 \%$. Campo Belo mostrouse como o município mais problemático à instalação de lavouras cafeeiras apresentando $1 \%$ de suas lavouras cafeeiras instaladas em áreas entre 51 e 75\% de declividade. A maioria de suas lavouras (45\%) encontra-se instalada em áreas entre 0 e $10 \%$ de declividade. Em Cristais, 69\% das lavouras encontram-se instaladas em áreas com declividade entre 0 e $10 \%$.

\subsection{Orientação de Vertentes e Cafeicultura}

Conforme a Figura 16, verifica-se que em
Aguanil, 26,34\% do café é cultivado em terrenos com orientação de vertentes a noroeste sentido norte e 22,72\% em áreas com orientação nordeste sentido norte, indicando condições propícias à instalação da cafeicultura em relação à variável supramencionada. As áreas localizadas em vertentes a sudeste e sudoeste são aquelas que possuem o menor percentual de cultivo, com 5,28\% e 5,02\% respectivamente com restrições ao cultivo de café conforme ALZUGARAY e ALZUGARAY (1985).

Em Boa Esperança, as lavouras de café apresentam-se bem estratificadas nas diferentes faces de relevo, não existindo um perfil de cultivo bem definido. Neste município, 17,94\% das lavouras estão instaladas em áreas com vertentes a nordeste sentido norte e 13,83\% em áreas com orientação a noroeste, sentido norte, locais onde a cultura apresenta as melhores condições de instalação se considerarmos a variável supramencionada. Porém, é representativa a área cultivada em vertentes a sudeste e sudoeste, com 10,69\% e 9,25\%, respectivamente (Figura 16).
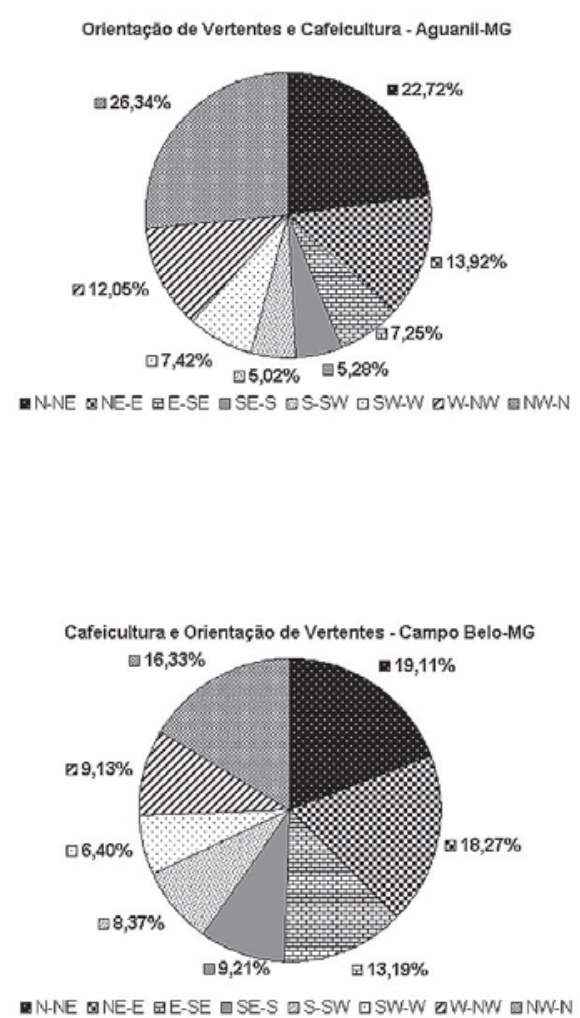

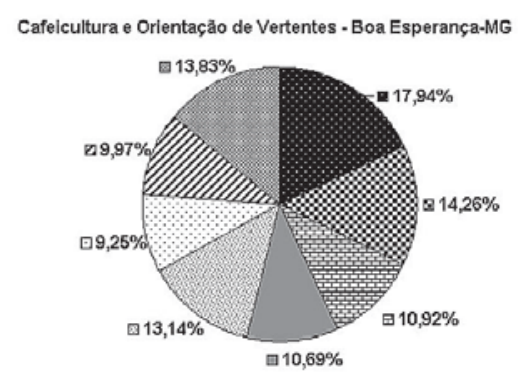

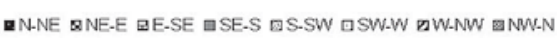

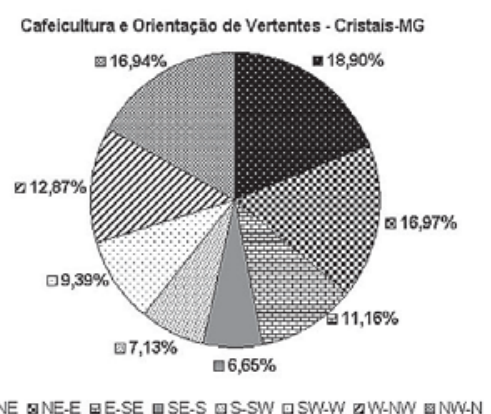

Figura 16. Orientação de vertentes e cafeicultura em Aguanil, Boa Esperança, Campo Belo e Cristais. 
Em Campo Belo, a situação é semelhante a Aguanil. Neste município 16,33\% das áreas são cultivadas em terrenos orientados a noroeste sentido norte e 19,11\% em áreas a nordeste, sentido norte, indicando que as áreas com café seguem as recomendações técnicas de instalação. As áreas localizadas em vertente sudeste e sudoeste sentido sul representam 9,21\% e 8,37\%, respectivamente, e são consideradas as áreas com maior limitação à implantação de cafezais.

Em Cristais, 18,90\% das áreas com café possuem orientação a nordeste sentido norte e 16,94\% das áreas são orientadas a noroeste sentido norte, apresentando com isso as lavouras com melhor instalação se considerarmos somente a condição de vertentes. As áreas com maior limitação a sudeste e
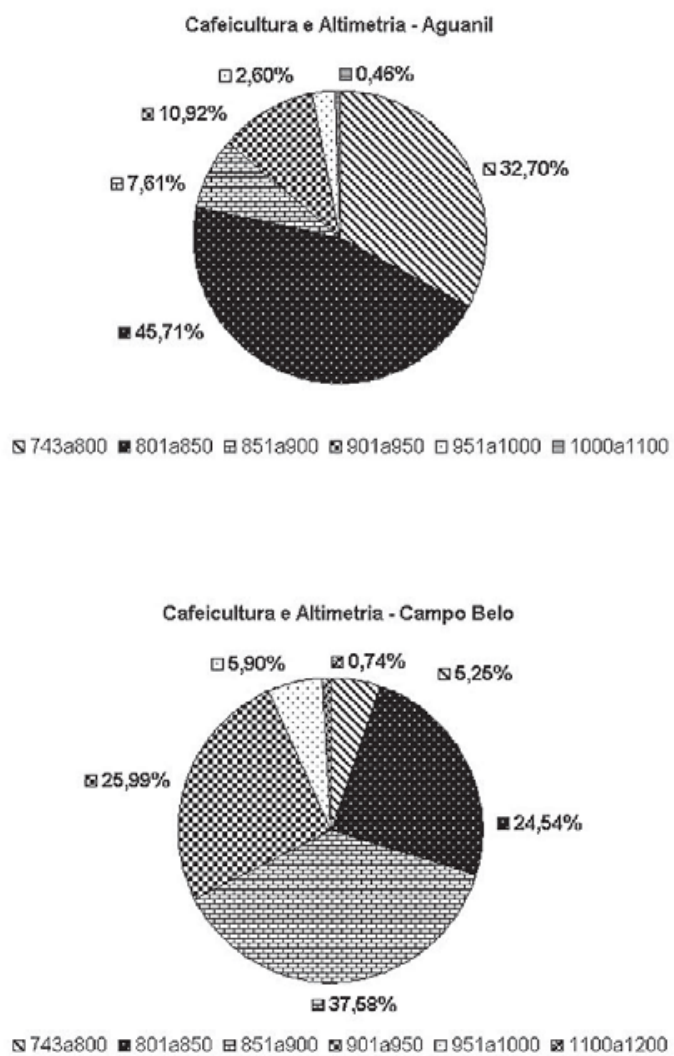

sudoeste sentido sul representam 6,65\% e 7,13\%, respectivamente.

\subsection{Altimetria e Cafeicultura}

Na Figura 17 verifica-se que em Aguanil, Boa Esperança, Campo Belo e Cristais 45,71\%, 38,81\%, $24,54 \%$ e $60,91 \%$ respectivamente das áreas cultivadas com café estão instaladas entre 801 e 850 m de altitude. Não se constatou valores de altimetria limitantes à cafeicultura no município conforme recomendações de SEDIYAMA (2001). Todos os municípios possuem a maioria das lavouras instaladas entre 801 e 850 m, com exceção de Campo Belo, em que predominam as áreas cultivadas entre 851 e $900 \mathrm{~m}$.
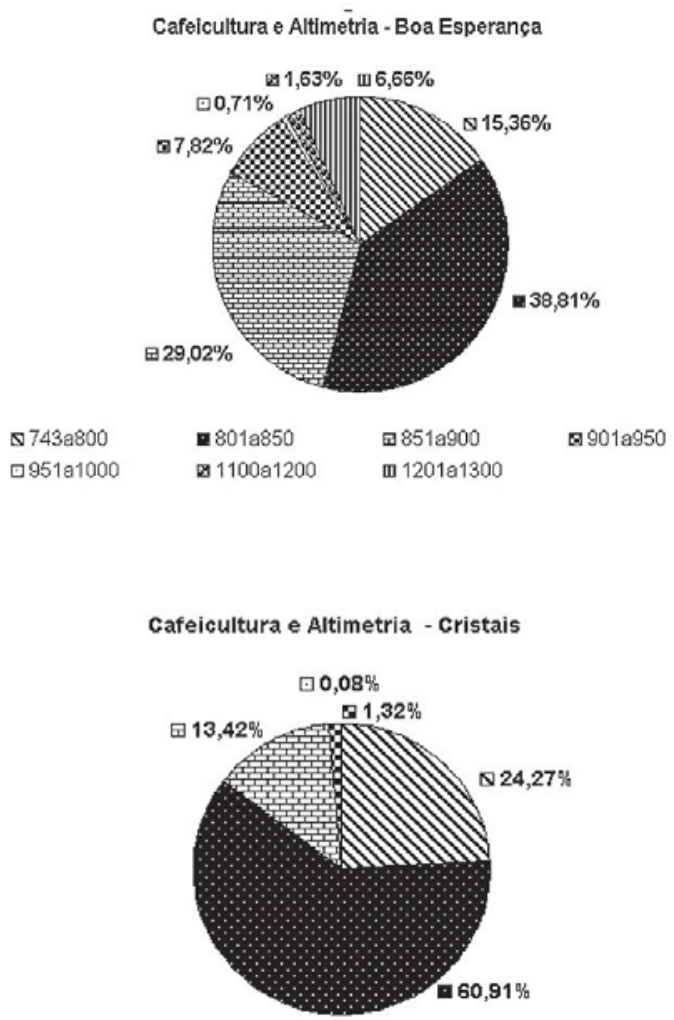

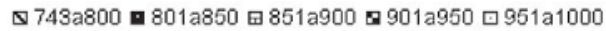

Figura 17. Caracterização da cafeicultura em relação a altimetria.

\section{CONCLUSÃO}

A utilização dos dados SRTM para o cálculo das variáveis declividade e orientação de vertentes permitiu a parametrização do espaço geográfico e sua respectiva representação espacial. O método 
utilizado mostrou-se eficaz no cálculo das variáveis e a integração de dados em um sistema de informação geográfica permitiu a análise das variáveis em escala municipal.

Foi possível a caracterização das lavouras cafeeiras situadas nos municípios de Aguanil, Boa Esperança, Campo Belo e Cristais. Os municípios com as características mais favoráveis à cafeicultura são Boa Esperança e Cristais. Já Aguanil e Campo Belo, possuem algumas restrições naturais ao cultivo em relação principalmente à declividade e solos.

\section{REFERÊNCIAS BIBLIOGRÁFICAS}

ALZUGARAY, D.; ALZUGARAY, C. Flora brasileira. São Paulo, SP: Três Livros, 1984.

AMARAL, F.C.S; PEREIRA, N.R.; CARVALHO Junior, W. Principais limitações dos solos brasileiros. EMBRAPA Solos. 1999. Disponível em: <www. cnps.embrapa.br/serch/pesqs/tema3/tema3.html>. Acesso em: 15 jul. 2005

ASSAD, E.D.; SANO, E.E. Sistema de Informações Geográficas: aplicações na agricultura. Brasília: EMBRAPA, 1998. 434P.

ASSOCIAÇÃO BRASILEIRA DA INDÚSTRIA DO CAFÉ (ABIC). Cafeicultura. Boletim Técnico, n.355, 4p., 2003. Disponível em: <www.abic.com.br/ arquivos/> . Acesso em: 06 jan. 2005.

BARROS, M.A. Geotecnologias como contribuição ao estudo do Agroecossistema cafeeiro de Minas Gerais em nível municipal. Dissertação (Mestrado em Sensoriamento Remoto) - Instituto Nacional de Pesquisas Espaciais, São José dos Campos. Maio 2006.

BURROUGH, P. A.; MCDONNELL, R.A. Principles of geographical information systems. Oxford: Oxford University Press, 1998. 329 p

CÂMARA, G.; SOUZA, R.C.M.; FREITAS, U.M.; GARRIDO, J. SPRING: Integrating remote sensing and GIS by object-oriented data modelling. Computers e Graphics, v. 20, n.3, p. 395-403, maiojunho 1996.

COMPANHIA DE TECNOLOGIA DA INFORMAÇÃO DO ESTADO DE MINAS GERAIS (PRODEMGE). Limite dos Municípios de Minas Gerais. Belo Horizonte,1998. Escala 1:100.000. Disponível em:< http://www.geominas.mg.gov.br/>. Acesso em: 15 mar. 2005.

CREPANI, E.; MEDEIROS, J.S.; FILHO, P.H.; FLORENZANO, T.G.; DUARTE, V.; BARBOSA, C.C.F. Sensoriamento remoto e geoprocessamento aplicados ao zoneamento ecológicoeconômico e ao ordenamento territorial. São José dos Campos: Instituto Nacional de Pesquisas Espaciais, 2001. 101 p. (INPE-8454-RPQ/722).

CREPANI, E.; MEDEIROS, J.S. Imagens fotográficas derivadas de MNT do Projeto SRTM para fotointerpretação na geologia, geomorfologia e pedologia. São José dos Campos: Instituto Nacional de Pesquisas Espaciais, 2004. 39 p. (INPE-11238$\mathrm{RPQ} / 761)$.

EINEDER, M.; RABUS, B.; ROTH, A.; BAMLER, $\mathrm{R}$. The shuttle radar topography mission - a new class of digital elevation models acquired by spaceborne radar. Journal of Photogrammetry \& Remote Sensing, v.57, n.1, p. 241-262, jan. 2003.

FELGUEIRAS, C.A.; ERTHAL, G.J. Aplicações de modelos numéricos de elevação e integração com imagens digitais. São José dos Campos: Instituto Nacional de Pesquisas Espaciais, 1988. (INPE-4776PRE/1445)

GAO, J. Comparison of sampling schemes in construction DTMs from topographic maps. ITC Journal, n.1, p.18-22, 1995.

INSTITUTO BRASILEIRO DE GEOGRAFIA E ESTATÍSTICA (IBGE): Folha Campo Belo. SF23-Y-D-II-1 MI-2769/1. Brasília, 2005. 3 Mapas. Escala 1:50.000. Disponível em: <http://www.ibge. 
gov.br>. Acesso em: 12 mar. 2005.

KURKDJIAN, M.L.N.O.; VALÉRIO FILHO, M.; VENEZIANE, P.; PEREIRA, M.N.; FLORENZANO, T.G.; ANJOS, C.E.; OHARA, T.; DONIZETI, P.L.; ABDON, M.M.; SAUSEN, T.M.; PINTO, S.A.F.; BERTOLDO, M.A.; BLANCO, J.G.; CZORDA, S.M. Macrozoneamento da região do Vale do Paraíba e Litoral Norte do Estado de São Paulo. São José dos Campos, INPE, 1992.176p. (INPE 5381-PRP/165).

LI, Z. Variation of the accuracy of digital terrain models with sampling interval. Photogrammetric Record, v.14, n.79, p.113-128, 1992.

MATIELLO, J.B. Café: do cultivo ao consumo. São Paulo: Globo, 1991. 320p.

MINISTÉRIO DAAGRICULTURA(MA). Levantamento de Reconhecimento dos Solos da Região sob Influência do Reservatório de Furnas. Rio de Janeiro, 1962. 462 p.

MINITAB. Minitab Statistical Tab. 2000. 1Cd Rom.

NATIONAL AERONAUTICS AND SPACE ADMINISTRATION (NASA). Shuttle Radar Topography Mission (SRTM) data product. California, 2005. 2 produtos. SRTM - S21W046 e S22W046. Disponível em: < http://www2.jpl.nasa.gov/srtm/ dataprelimdescriptions.html $>$. Acesso em: 20 jan. 2005.

ÖZDAMAR, L.; DEMIRHAN, M; ÖZPINAR, A. A comparison of spatial interpolation methods and fuzzy areal evaluation scheme in environmental site characterization. Computers Environment and Urban Systems, v.23, n.5, p. 399-423, 1999.

REISS, P. High-quality DTMs. GIM International, v. 16, p. 40-43, 2002.

SEDIYAMA, G.C.; MELO JUNIOR, J.C.; SANTOS, A.R.; RIBEIRO, A.; COSTA, M.H.; HAMAKAWA, P.J.; COSTA, J.M.N.; COSTA, L.C. Zo- neamento agroclimático do cafeeiro (Coffea arabica L.) para o Estado de Minas Gerais. Revista Brasileira de Agrometeorologia, v. 9, p.501-509, 2001.

THE ENVIRONMENT FOR VISUALIZING IMAGES (ENVI) 4.1. Boulder, CO: Research Systems. 2004

VALERIANO, M.M.; MORAES, J.F.L. Extração de rede de drenagem e divisores por processamento digital de dados topográficos. In: Simpósio Brasileiro de Sensoriamento Remoto, 10., Foz do Iguaçu, 2001. Anais... São José dos Campos: Instituto Nacional de Pesquisas Espaciais, 2001.

VALERIANO, M.M. Modelo digital de elevação com dados SRTM disponíveis para a América do Sul. São José dos Campos: Instituto Nacional de Pesquisas Espaciais, 2004. 72p.

VAN ZYL, J.J. The Shuttle Radar Topography Mission (SRTM): a breakthrough in remote sensing of topography. Acta Astronáutica, v.48, n.5-12, p.559-565, 2001.

WOOD, J. The geomorphological characterisation of Digital Elevation Models. 1996. 184p. Tese (Doutorado em Information Science) - City University of London, London, 1996.

ZIMBACK. C.R.L. Mapa de solos da bacia do Rio Pardo (SP). Botucatu: Universidade Estadual Paulista, 1997. 55 p. 